\section{Using Steam In Immunochestochemistry}

I have used steaming for immunohistochemisty (IHC) and in situ hybridization (ISH), and it takes advantage of the very consistent temperature maintained in the steam chamber of a common household vegetable steamer (I.e., Black and Decker Handy Steamer series). A Coplin jar or any other slide-holding container which contains a volume of preheated retrieval solution can be maintained at $98^{\circ} \mathrm{C} \pm 1-2^{\circ}$ for up to one hour (or more depending on the steamer model and if one adds additional water to the lower chamber).

If one subscribes to the concept that microwaves play an important role in epitope/tqarget retrieval then this would not be a method of choice, but based on many comparative studies between microwave and steam retrieval (personal observations), the results are consistent if not better with steam, especially for $\mathrm{IHC}$, and superior morphology is normally retained in the specimen. For unexplained reasons, in our experience, microwaves still are superior for ISH, but I think the reasons may be related to intensity and duration, although I'm not discounting a possible role of the actual microwave irradiation.

Timothy Plummer, Mayo Clinic

\section{Filtering to Show DNA and RNA Separately in Slides Stained for Both Nucleic Acids}

The methyl green-pyronine (MGP) method stains RNA (in nucleoli and cytoplasm) pinkish-red and DNA (in nuclear chromatin) bluish-green. Here is a simple trick for demonstrating the two nucleic acids separately. Place a petri dish containing either a diluted methyl green or a diluted pyronine solution below the condenser of the microscope. (It is assumed that the microscope has its illuminator in the base of the stand.) Using a dropper, adjust the concentration of the dye in the dish until the background color matches the intensity of the stained RNA or DNA in the section. Sites containing the other nucleic acid stand out darkly against a background of contrasting color.

Photograph the preparation on black-and-white film, and print so that the background is white or pale gray. This gives pleasing results with the central nervous system, providing almost complete separation of neurons (RNA in cytoplasm and nucleoli) and neuroglial cells (DNA in nuclei). A neuronal nucleus contains the same complement of DNA as any other somatic cell, but typically diluted in a volume of nucleoplasm too large to allow easily visible staining.

This filtering method is not perfect. It does not even separate all neurons from all glial cells. Small neurons such as cerebellar granule cells have nuclei with the DNA condensed enough to stain strongly with methyl green, and pyronine-stained RNA can be seen in the cytoplasm of some oligodendrocytes, especially with an oil immersion objective. Chromotropic materials (including mast cell granules, cartilage matrix and several types of mucus) are stained orange by pyronine in the MGP method. This metachromatic color is not eliminated by a filter containing pyronine or methyl green, but it is easily recognized when looking at an MGP-stained slide without a dye-containing filter.

For control purposes, the sections should be photo- graphed with both the methyl green and the pyronine filters, used in sequence, and without any filtering (using black and while film as described above).

\section{J. A. Kieman, The University of Westem Ontario kieman@uwo.ca}

\section{Mounting Small Insects}

I have mounted small insects using the following method:

1) Get some dissecting pins, preferably, or any very thin rigid pin or wire and cut about $1 / 4$ inch long.

2) Mount it vertically on an SEM stub using carbon paint, or any quick drying glue, and let it dry completely, put in warming oven to speed it up, or use hair dryer.

3) Position the fly heads upsidedown on clean surface, like lens tissue or glass petri dish.

4) Put a fresh drop of carbon paint, or glue, on a nearby surface, pick up the SEM stub with stub handling forceps, dip the tip of the pin into the fresh paint or glue just enough to get a tiny little blob on the pin head, then under a dissecting or low power scope touch the tip of the pin to the back surface of the fly head. It should stick and you can pick it up at that point, place right side up and let dry completely.

5) Coat in vacuum evaporator or sputter coater as usual. After the coating run, vent gas into chamber slowly to not disturb delicate sample.

Its a bit of a prep, but you also get the fly head off the stub surface, little or no background junk in the view. Good luck!

Gib Ah/strand, University of Minnesota giba@puccini.cdl.umn.edu

\section{A Tip on the Care of Water in Instrument Chillers}

Preparation of the water in water chillers is a strange world of its own and there are many possible ways to do this. The majority of my experience has been with the Haskris systems, but the chemistry may be the same for other systems. In about 30 years of looking after many chillers, my formula for success goes like this:

1) Use deionized or distilled water. The water will leach enough products from the hoses, microscope lenses, pumps and so forth to reach an equilibrium and will then be "ideally suited" for your system.

2) Don't use any fungicide or other bug killer because it will slime up the works.

3) Put 4 or 5 drops of oil on top of the water reservoir. This will form a barrier by creating a monolayer on top of the water and keep oxygen from diffusing into the water, and things from growing in it.

I have used this procedure in tropical climates and in the north, in both dry and humid environments and it has always worked very well. I can almost guarantee you that ethylene glycol will gum up the works.

Alex Greene, Scientific Instrumentation Services, Inc. ablue@io.com 